\title{
Speciation analysis of inorganic antimony in airborne particulate matter employing slurry sampling and HG QT AAS
}

\author{
Sergio L. C. Ferreira, ${ }^{* a b}$ Samuel M. Macedo, ${ }^{a b d}$ Debora C. dos Santos, ${ }^{a b}$ Raildo M. de Jesus, ${ }^{a b c}$ \\ Walter N. L. dos Santos, ${ }^{b d}$ Antonio F. de S. Queiroz ${ }^{e}$ and Jailson B. de Andrade ${ }^{a b}$ \\ Received 23rd March 2011, Accepted 28th April 2011 \\ DOI: $10.1039 / \mathrm{c} 1 \mathrm{ja10108k}$
}

\begin{abstract}
The present paper proposes an analytical procedure for speciation analysis of inorganic antimony in airborne particulate matter using slurry sampling and hydride generation atomic absorption spectrometry (HG QT AAS). During the antimony determination, a quartz $\mathrm{T}$ tube cell was heated to approximately $900{ }^{\circ} \mathrm{C}$ using air-acetylene flame. The optimization step was performed by employing full two-level factorial and Box-Behnken designs involving the following factors: flow rate and concentration of sodium tetrahydroborate and hydrochloric acid concentration, having as chemometric response absorbance. Using the optimized conditions, the method employing slurry sampling allows for the determination of total $\mathrm{Sb}$ and $\mathrm{Sb}$ (III) with limits of quantification of 0.3 and 0.2 $\mu \mathrm{g} \mathrm{L}^{-1}$, respectively. The precision, expressed as a relative standard deviation (\%RSD), was always lower than $6.2 \%$. The accuracy was confirmed by analysis of a certified reference material of atmospheric particulate matter urban dust furnished by National Institute of Standards \& Technology. This method was used to determine total antimony and antimony(III) in four particulate matter samples collected in Bananeira Village, Bahia State, Brazil. In these samples, total antimony concentrations varied from 4.32 to $4.60 \mathrm{ng} \mathrm{m}^{-3}$, and $\mathrm{Sb}$ (III) concentrations varied from 0.33 to $0.67 \mathrm{ng} \mathrm{m}^{-3}$.
\end{abstract}

\section{Introduction}

Antimony is a toxic chemical element, even at very low concentrations, with no known biological functions. ${ }^{1-4}$ In elemental form, antimony is more toxic than its corresponding salts. In addition, the inorganic species are more toxic than the organic species. In speciation studies, only the following three antimony species are generally considered: the two oxyanions, antimonite $\mathrm{Sb}$ (III) and antimonate $\mathrm{Sb}(\mathrm{v})$, and the trimethylantimony ion $\left(\mathrm{Me}_{3} \mathrm{Sb}\right) .{ }^{1,2,5}$ Antimony(III) compounds are about 10 times more toxic than antimony(v) compounds. ${ }^{2}$ All of these species generate volatile hydrides in acidic media with sodium tetrahydroborate solutions, although the $\mathrm{Me}_{3} \mathrm{Sb}$ shows a poorer signal than the others.

Dietl et al. $^{6}$ collected atmospheric particulate matter at two locations in Munich, Germany with different traffic impacts. The results achieved varied from 1.26 to $13.6 \mathrm{ng} \mathrm{m}^{-3}$. Smichowski

${ }^{a}$ Instituto de Química, Universidade Federal da Bahia (UFBA), Campus de Ondina, 40170-290 Salvador, BA, Brazil.E-mail: slcf@ufba.br; Fax: +5571-3235-5166

${ }^{b}$ Instituto Nacional de Ciência e Tecnologia, INCT, de Energia e Ambiente, 40170-290 Salvador, BA, Brazil

'Universidade Estadual de Santa Cruz (UESC), Ilhéus, BA, Brazil

${ }^{d}$ Universidade do Estado da Bahia, CEP, 91501-970 Salvador, BA, Brazil

${ }^{e}$ Universidade Federal da Bahia, Instituto de Geociências, CEP, 40170-270

Salvador, BA, Brazil et $a .^{7}$ evaluated the elemental content of airborne particulate matter samples collected in Buenos Aires, Argentina. The results found for antimony varied from 0.9 to $15.3 \mathrm{ng} \mathrm{m}^{3}$. MoredaPineiro et $a l^{8}$ found bismuth, arsenic, tin and antimony in atmospheric particulate matter collected in a non-polluted suburban area of A Coruna, Spain. The antimony concentrations found varied from 0.54 to $2.23 \mathrm{ng} \mathrm{m}^{3}$. Johansson et al. quantified antimony in atmospheric particulate matter collected over the course of a year in a high traffic street and at an urban background site in Stockholm, Sweden. The antimony concentrations found in the urban area varied from 0.22 to $5.1 \mathrm{ng} \mathrm{m}^{3}$, whereas concentrations in the high traffic street varied from 2.9 to $39 \mathrm{ng} \mathrm{m}^{3}$. The analysis was performed by inductively coupled plasma-mass spectrometry (ICP-MS). ${ }^{9}$

Most available methods for the determination of antimony in atmospheric particulate matter samples were established for the quantification of total antimony. However, only a few speciation studies involving antimony have been developed for these samples. These methods have been performed using basically a separation step involving high performance liquid chromatography (HPLC) in conjunction with an analytical detection technique. ${ }^{10,11}$ Iijima et al. proposed methods for speciation analysis of inorganic $\mathrm{Sb}(\mathrm{III})$ and $\mathrm{Sb}(\mathrm{v})$ in atmospheric particulate matter samples using HPLC-ICP-MS. ${ }^{12,13}$ Zheng et al. performed studies on the speciation of inorganic and organic antimony compounds in airborne particulate matter by HPLC-ICP-MS. ${ }^{14}$ 
Miravet et al. also used HPLC-ICP-MS for speciation analysis of antimony in extracts of size-classified volcanic ash. ${ }^{15}$ SanchezRodas et al. performed a procedure for the speciation of antimony in airborne particulate matter using ultrasound probe fast extraction, followed by HPLC separation and quantification employing hydride generation atomic fluorescence spectrometry (HG AFS). ${ }^{16}$

The use of slurry sampling in the determination of volatile elements is of particular relevance in overcoming analyte loss, which is frequently encountered with conventional batchwise wet-chemical mineralization procedures. ${ }^{17}$ Cal-Prieto et al. proposed and evaluated several slurry sampling procedures for the determination of antimony in atmospheric particulate matter and marine sediments using electrothermal atomic adsorption spectrometry (ET AAS). ${ }^{18}$

In recent years, chemometric tools have often been applied to the optimization of analytical methods, ${ }^{19-22}$ considering their great advantage. ${ }^{23,24}$

This paper reports the first application of slurry sampling in conjunction with hydride generation for the determination of total antimony and antimony(III) in atmospheric particulate matter. The optimization step was performed using a factorial design and Box-Behnken matrix. This method was applied for speciation analysis of four samples collected in Bananeira Village in Bahia, Brazil.

\section{Experimental}

\subsection{Instrumentation and chemicals}

All reagents were of analytical grade (Merck, Darmstadt, Germany). All solutions were prepared using deionized water obtained through a Milli-Q system (resistivity $18.2 \mathrm{M} \Omega \mathrm{cm}$ ). Stock solutions of antimony(III) and antimony(v) at $1000 \mathrm{mg} \mathrm{L}^{-1}$ were prepared by dissolution of antimony(III) chloride and antimony(v) chloride in a $20 \%$ hydrochloric $(\mathrm{HCl})$ acid solution. The final dilution was performed with deionized water. The stock solutions were stored at $4{ }^{\circ} \mathrm{C}$. Working solutions of antimony (0.1-5.0 $\left.\mu \mathrm{g} \mathrm{L}^{-1}\right)$ were prepared daily using appropriate dilutions from the stock solution with deionized water. A $2 \mathrm{~mol} \mathrm{~L}^{-1} \mathrm{HCl}$ solution was prepared from concentrated $\mathrm{HCl}(37 \% \mathrm{v} / \mathrm{v}$, Merck). Aqueous solutions of $2.14 \%(\mathrm{w} / \mathrm{v})$ sodium tetrahydroborate $\left(\mathrm{NaBH}_{4}\right)$ were freshly prepared each day by dissolving the solid reagent in $0.5 \%(\mathrm{w} / \mathrm{v}) \mathrm{NaOH}$ (Merck) and then filtering the solution through a $0.45 \mu \mathrm{m}$ membrane. Additionally, prereducing solutions, containing $10 \%(\mathrm{w} / \mathrm{v})$ potassium iodide and $2.0 \%$ ascorbic acid, were freshly prepared in water. The reaction of hydride generation is carried out in a conical flask, which has three connections, one for addition of sodium tetrahydroborate solution, other for addition of argon and a third that is used to outlet the generated hydride and purge gas. The determination of total antimony and antimony(III) was performed using a Varian model SpectrAA 220 (Mulgrave, Victoria, Australia) flame atomic absorption spectrometer (FAAS) with antimony hollow cathode lamp light source $(217.6 \mathrm{~nm})$. The lamp had a current of $10 \mathrm{~mA}$ and a $0.5 \mathrm{~nm}$ slit width. A deuterium lamp was used for background correction. During the antimony determination, a quartz T tube cell, with a path-length of $165 \mathrm{~mm}$ and a diameter of $12 \mathrm{~mm}$, was heated to approximately $900{ }^{\circ} \mathrm{C}$ using air- acetylene flame. The sample slurries were sonicated using a VWR model $75 \mathrm{D}$ ultrasonic bath at room temperature. The flame composition was acetylene (flow rate $2.0 \mathrm{~L} \mathrm{~min}^{-1}$ ) and air (flow rate $13.5 \mathrm{~L} \mathrm{~min}^{-1}$ ). An Alitea C-6 XV (Stockholm, Sweden) peristaltic pump, fitted with Tygon tubes, was used for propelling all solutions. High purity $(99.99 \%)$ argon was used as the purge

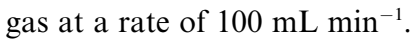

\subsection{Standard reference material and real samples}

In this work, a standard reference material of atmospheric matter urban dust (SRM 1649a), furnished by National Institute of Standards \& Technology, was used for accuracy evaluation of the method. Four real samples of airborne particulate matter were collected in Bananeira, situated in Todos os Santos Bay (Bahia, Brazil). Bananeira is a small village located close to the port and to an industrial plant. The village is composed of approximately 1000 inhabitants, whose livelihood is based on handcraft work and fishery. Particulate matter was collected with a Hi-Vol sampler under an average flow rate of $1.16 \mathrm{~m}^{3} \mathrm{~min}^{-1}$ over $24 \mathrm{~h}$ sampling periods on quartz filters $(22.8 \times 17.7 \mathrm{~cm}$, Energética, RJ, Brazil) in July 2005. Sample masses were determined by weighing the filters before and after sampling, using an analytical balance (Sartorius Analytic, Goettingen, Germany). The filters were folded and wrapped in aluminium foil, put inside sealed plastic bags, and stored in the lab at $4{ }^{\circ} \mathrm{C}$ until analysis. Both the 1649a certified material and the four particulate matter filter samples from Bananeira were analyzed for atmospheric concentrations of inorganic antimony, as described below.

\subsection{Preparation of the sample slurries}

Prior to analysis, each individual particulate matter filter sample (real samples) was cut using stainless steel scissors into pieces smaller than $1 \mathrm{~cm}$ in length. The slurries were prepared by placing $20.0 \mathrm{mg}$ of sample and $4.0 \mathrm{~mL}$ of $4.0 \mathrm{~mol} \mathrm{~L}^{-1}$ hydrochloric acid into $25 \mathrm{~mL}$ volumetric flasks. Then, this mixture was sonicated at room temperature for $30 \mathrm{~min}$ and filled to the requisite volume with deionized water. Aqueous standard solutions were used to generate standard calibration curves. This same procedure was applied to the reference sample (Urban Dust SRM 1649a) and the samples from Bananeira.

\subsection{Batch procedures for speciation analysis of antimony}

2.4.1. Total antimony. For determination of total antimony, $3.0 \mathrm{~mL}$ of a $6 \mathrm{~mol} \mathrm{~L}^{-1}$ hydrochloric acid solution, $1 \mathrm{~mL}$ of prereducing solution (KI 10\% + ascorbic acid 2\%) and aliquots of the sample slurries were added to reaction flasks. After $30 \mathrm{~min}$, the resulting solutions were diluted to $10 \mathrm{~mL}$ with Milli-Q water. Sodium tetrahydroborate was introduced into the closed system at a flow rate of $2.00 \mathrm{~mL} \mathrm{~min}{ }^{-1}$ using a peristaltic pump for 15 seconds, and the hydride vapor generated was transported using argon (with a flow rate of $100 \mathrm{~mL} \mathrm{~min}{ }^{-1}$ for 30 seconds) to the quartz T-tube heated at $900{ }^{\circ} \mathrm{C}$ for quantification of antimony. The optimal time for analytical measurements was found to be from 15 to $25 \mathrm{~s}$. Calibration curves were generated by processing aqueous $\mathrm{Sb}(\mathrm{III})$ standards $\left(0.2-5.0 \mu \mathrm{g} \mathrm{L}^{-1}\right)$ using the same procedure. 
2.4.2. Antimony(III). For the determination of antimony(III), aliquots of the sample slurries were transferred to reaction flasks containing $1.0 \mathrm{~mL}$ of citric acid solution and diluted to a final volume of $10 \mathrm{~mL}$ with Milli-Q water. Sodium tetrahydroborate was introduced into the closed system at a rate of $2.00 \mathrm{~mL} \mathrm{~min}^{-1}$ using a peristaltic pump, and the hydride vapor generated was transported using argon to the quartz T-tube heated at $900{ }^{\circ} \mathrm{C}$ for the determination of antimony.

\section{Results and discussions}

\subsection{Optimization of the conditions for quantification of antimony(III)}

Optimization was performed using a full two-level factorial design involving the following variables: flow rate and concentration of sodium tetrahydroborate and hydrochloric acid concentration, having absorbance as chemometric response. The experimental dominions, expressed as coded and real values for each factor, and the absorbencies obtained in experiments are shown in Table 1. All experiments were carried out in a random order using $10.0 \mathrm{~mL}$ aliquots of a $3.0 \mu \mathrm{g} \mathrm{L} \mathrm{L}^{-1} \mathrm{Sb}$ (III) solution. The following factors were adjusted by considering previous experiments: sodium hydroxide concentration, pre-reducing solution and flow rate of argon.

The results of the factorial design were evaluated, and the effects of the variables on hydride generation were calculated similar to Bruns et al. ${ }^{25}$ The effect values were $(+0.0736 \pm$ $0.0007),(+0.0622 \pm 0.0007)$ and $(+0.0107 \pm 0.0007)$ for sodium tetrahydroborate concentration, flow rate of sodium tetrahydroborate and hydrochloric acid concentration, respectively. These data demonstrate that all three factors are statistically significant for hydride generation as can be seen in Pareto chart (Fig. 1). A curvature test ${ }^{26}$ was also applied, with the curvature calculated using the following equation: curvature $=R_{\mathrm{FD}}-R_{\mathrm{CP}}$, where $R_{\mathrm{ED}}$ is the average of the responses obtained from experiments specified by the factorial design, and $R_{\mathrm{CP}}$ is the average of the responses obtained for the central point. An analysis of the results, $R_{\mathrm{FD}}=(0.1959)$ and $R_{\mathrm{Cp}}=(0.2433)$, suggests a negative curvature, meaning that there is a maximum condition in the region of the central point of the experimental dominions established in the factorial design. On the basis of these results, a Box-Behnken design ${ }^{32,27}$ was performed to find

Table 1 Full two-level factorial design - optimization of the procedure for HG AAS

\begin{tabular}{lrrrl}
\hline Experiment & $\begin{array}{l}{\left[\mathrm{BH}_{4}^{-}\right] /} \\
(x \%, \mathrm{w} / \mathrm{v})\end{array}$ & $\begin{array}{l}\mathrm{FR}-\left[\mathrm{BH}_{4}^{-}\right] / \\
\mathrm{mL} \mathrm{min}^{-1}\end{array}$ & $\begin{array}{l}{[\mathrm{HCL}] /} \\
\mathrm{mol} \mathrm{L}\end{array}$ & Absorbance \\
\hline 1 & $-1(1.50)$ & $-1(1.00)$ & $-1(1.00)$ & 0.0921 \\
2 & $1(2.50)$ & $-1(1.00)$ & $-1(1.00)$ & 0.2223 \\
3 & $-1(1.50)$ & $1(3.00)$ & $-1(1.00)$ & 0.2063 \\
4 & $1(2.50)$ & $1(3.00)$ & $-1(1.00)$ & 0.2415 \\
5 & $-1(1.50)$ & $-1(1.00)$ & $1(3.00)$ & 0.1166 \\
6 & $1(2.50)$ & $-1(1.00)$ & $1(3.00)$ & 0.2281 \\
7 & $-1(1.50)$ & $1(3.00)$ & $1(3.00)$ & 0.2214 \\
8 & $1(2.50)$ & $1(3.00)$ & $1(3.00)$ & 0.2387 \\
$9(\mathrm{C})$ & $0(2.00)$ & $0(2.00)$ & $0(2.00)$ & 0.2441 \\
$10(\mathrm{C})$ & $0(2.00)$ & $0(2.00)$ & $0(2.00)$ & 0.2422 \\
$11(\mathrm{C})$ & $0(2.00)$ & $0(2.00)$ & $0(2.00)$ & 0.2435 \\
\hline
\end{tabular}

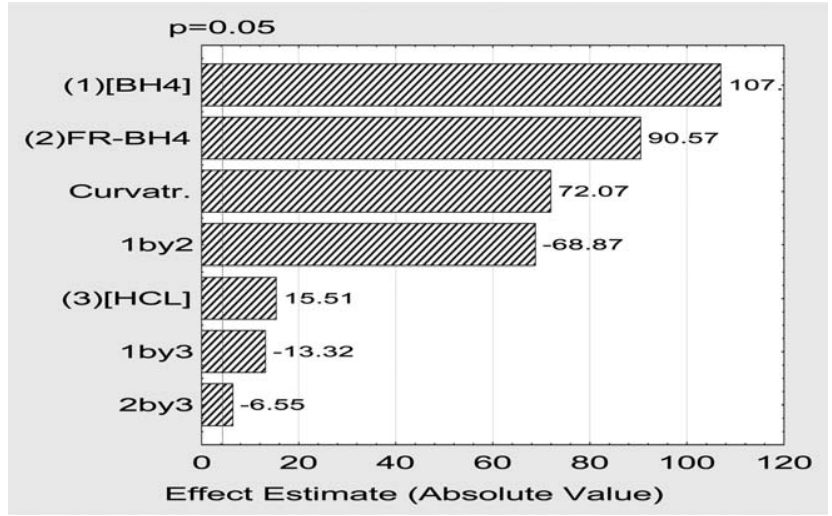

Fig. 1 Pareto chart of the two-level factorial design.

the best experimental conditions for hydride generation. Coded and real values, as well as the absorbencies are shown in Table 2.

The data from this approach were evaluated. Considering only the significant terms, the quadratic model obtained is as follows:

$$
\begin{gathered}
\text { Abs }=0.2553+0.0382\left[\mathrm{NaBH}_{4}\right]-0.0863\left[\mathrm{NaBH}_{4}\right]^{2}+0.0249 \\
{\left[\mathrm{NaBH}_{4}\right][\mathrm{HCl}]}
\end{gathered}
$$

This model does not present a lack of fit $(p=0.056)$, and it shows a maximum condition for the absorbance, with critical values of the variables (as coded values) of 0.281 for $\left[\mathrm{NaBH}_{4}\right]$, 0.122 for flow rate of $\mathrm{NaBH}_{4}$ and 0.477 for [HCl]. These coded values, as real values, are $2.14 \%(\mathrm{w} / \mathrm{v}), 2.12 \mathrm{~mL} \mathrm{~min}^{-1}$ and $2.48 \mathrm{~mol} \mathrm{~L}^{-1}$, respectively. The model also demonstrates that the flow rate of $\mathrm{NaBH}_{4}$ and all of its interactions are not significant. This result means that the variation of this factor, in the range of 1.00 to $3.00 \mathrm{~mL} \mathrm{~min}{ }^{-1}$, does not affect the chemometric response (absorbance). Considering these results, the general procedure established by the method recommends using a $2.14 \%$ (w/v) $\mathrm{NaBH}_{4}$ solution with a flow rate of $2.0 \mathrm{~mL} \mathrm{~min}^{-1}$ and hydrochloric acid solution at a concentration higher than $2.0 \mathrm{~mol} \mathrm{~L}^{-1}$.

Table 2 Box-Behnken design - optimization of the procedure for HG

\begin{tabular}{|c|c|c|c|c|}
\hline Experiment & $\begin{array}{l}{\left[\mathrm{BH}_{4}^{-}\right] /} \\
\left(x^{0} \%, \mathrm{w} / \mathrm{v}\right)\end{array}$ & 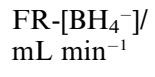 & $\begin{array}{l}{[\mathrm{HCL}] /} \\
\mathrm{mol} \mathrm{L}^{-1}\end{array}$ & Absorbance \\
\hline 1 & -1 & -1 & 0 & 0.0932 \\
\hline 2 & 1 & -1 & 0 & 0.1755 \\
\hline 3 & -1 & 1 & 0 & 0.1623 \\
\hline 4 & 1 & 1 & 0 & 0.1908 \\
\hline 5 & -1 & 0 & -1 & 0.1361 \\
\hline 6 & 1 & 0 & -1 & 0.1839 \\
\hline 7 & -1 & 0 & 1 & 0.0784 \\
\hline 8 & 1 & 0 & 1 & 0.2256 \\
\hline 9 & 0 & -1 & -1 & 0.2301 \\
\hline 10 & 0 & 1 & -1 & 0.1997 \\
\hline 11 & 0 & -1 & 1 & 0.2493 \\
\hline 12 & 0 & 1 & 1 & 0.2358 \\
\hline 13 & 0 & 0 & 0 & 0.2499 \\
\hline 14 & 0 & 0 & 0 & 0.2650 \\
\hline 15 & 0 & 0 & 0 & 0.2509 \\
\hline
\end{tabular}
AAS 


\subsection{Preparation of slurry sampling for determination of antimony}

To determine the experimental conditions for antimony extraction from filter samples containing particulate matter, several slurries were prepared in $25 \mathrm{~mL}$ volumetric flasks using $20.0 \mathrm{mg}$ of filters and $4 \mathrm{~mL}$ of the hydrochloric acid solutions. The concentrations of the hydrochloric acid solutions varied from 0.0 to $12.0 \mathrm{~mol} \mathrm{~L}^{-1}$. These mixtures were sonicated at room temperature for $30 \mathrm{~min}$ and filled to a final volume with deionized water. The results demonstrate that in aqueous media, the antimony extraction is $60 \%$. Using hydrochloric acid solutions with concentrations greater than or equal to $2.0 \mathrm{~mol} \mathrm{~L}^{-1}$, the extraction is always quantitative, with recoveries ranging from 93 to $104 \%$. These experiments were performed using a certified reference material, and the quantification was carried out for total antimony employing pre-reducing solution. Therefore, the procedure proposed for slurry preparation recommends the use of $4 \mathrm{~mL}$ of $2 \mathrm{~mol} \mathrm{~L}^{-1}$ hydrochloric acid solutions.

\subsection{Optimization of the speciation procedure}

Both antimony(III) and antimony(v) react with sodium tetrahydroborate to form hydrides. However, some papers ${ }^{28}$ have reported the use of citric acid as an efficient masking reagent for antimony(v). As a result, the speciation procedure was established. First, solutions containing $\mathrm{Sb}(\mathrm{III})$ and $\mathrm{Sb}(\mathrm{v})$ were prepared, and the amount of citric acid necessary for masking Sb (v) was determined. The experiments were performed using solutions of $\mathrm{Sb}(\mathrm{III})$ and $\mathrm{Sb}(\mathrm{v})\left(3.0 \mu \mathrm{g} \mathrm{L}^{-1}\right)$ and citric acid $(0.5 \mathrm{~mol}$ $\mathrm{L}^{-1}$ ) in $10 \mathrm{~mL}$ volumetric flasks. The results demonstrate that

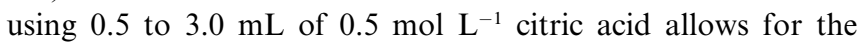
determination of antimony(III) in the presence of antimony(v). Therefore, the general procedure for antimony(III) quantification recommends using $1.0 \mathrm{~mL}$ of $0.5 \mathrm{~mol} \mathrm{~L}^{-1}$ citric acid solution.

To determine the total antimony, $\mathrm{Sb}(\mathrm{v})$ should first be reduced to $\mathrm{Sb}(\mathrm{III})$. Data presented in other papers ${ }^{29,30}$ show that $1.0 \mathrm{~mL}$ of pre-reducing solution (KI 10\% + ascorbic acid 2\%) can also be satisfactorily used. The time for analytical measurements was evaluated, and the results demonstrated that the analytical signals during the hydride generation are practically constant in the range from 15 to $25 \mathrm{~s}$.

\subsection{Validation studies}

Using the optimized experimental conditions, the method published herein allows for the determination of total antimony and $\mathrm{Sb}(\mathrm{III})$ with a linear function of the antimony concentration in the range of $0.3-5.0 \mu \mathrm{g} \mathrm{L}^{-1}$ for total antimony and $0.2-5.0 \mu \mathrm{g} \mathrm{L}^{-1}$ for $\mathrm{Sb}$ (III). The regression equations for total antimony and $\mathrm{Sb}(\mathrm{III})$ are $A_{\mathrm{Sb} \text { total }}=0.0847 C+0.0080\left(R^{2}=0.9997\right)$ and $A_{\mathrm{Sb}(\mathrm{III})}=$ $0.0851 C+0.0062\left(R^{2}=0.9998\right)$, respectively, where $A$ is the absorbance and $C$ is the concentration of Sb in $\mu \mathrm{g} \mathrm{L}^{-1}$. The limits of detection (LD) and quantification (LQ) for total antimony and antimony(III) were calculated using the IUPAC recommendation, ${ }^{31}$ where $\mathrm{LD}=(3 \sigma / S)$ and LQ $=(10 \sigma / S)$, with $(\sigma)$ as the standard deviation of the blank solution measurements and $(S)$ as the slope of the analytical curve. The LD and LQ obtained for total antimony and antimony(III) are 0.1 and $0.3 \mu \mathrm{g} \mathrm{L}^{-1}$ and 0.06 and $0.2 \mu \mathrm{g} \mathrm{L}^{-1}$, respectively. The detection limits found in this
Table 3 Determination of total $\mathrm{Sb}$ and $\mathrm{Sb}$ (III) in real samples of atmospheric particulate matter $(N=3)$

\begin{tabular}{lll}
\hline Sample & $\begin{array}{l}\text { Total antimony } \\
\mathrm{m}^{-3}\end{array}$ & Antimony $(\mathrm{III})^{a} / \mathrm{ng} \mathrm{m}^{-3}$ \\
1 & $4.60 \pm 0.25$ & $0.56 \pm 0.07$ \\
2 & $4.32 \pm 0.67$ & $0.33 \pm 0.02$ \\
3 & $4.40 \pm 0.45$ & $0.65 \pm 0.02$ \\
4 & $4.47 \pm 0.21$ & $0.67 \pm 0.04$ \\
${ }^{a}$ Results as interval confidence at $95 \%$ level. \\
\hline
\end{tabular}

work are comparable to other studies developed for determination of antimony based on hydride generation. ${ }^{32,33}$ Precision was evaluated as a relative standard deviation (\%RSD) and was lower than $6.23 \%$. The accuracy of the method was confirmed by analysis of the certified reference material of atmospheric particulate matter urban dust SRM 1649a, furnished by National Institute of Standards and Technology (Gaithersburg, MD, USA), being that the concentrations of total antimony and antimony(III) found with this method were, respectively $28.5 \pm$ 1.3 and $6.5 \pm 0.6 \mathrm{mg} \mathrm{kg}^{-1}$. The certified value for total antimony in this CRM is $29.9 \pm 0.7 \mathrm{mg} \mathrm{kg}^{-1}$.

\subsection{Speciation analysis of antimony in airborne particulate matter samples}

The method proposed was applied for speciation analysis of inorganic antimony in four atmospheric particulate matter samples collected in Bananeira, located in Todos os Santos Bay (Bahia, Brazil). First, antimony(III) was determined by HG AAS in the presence of citric acid as a mask for antimony(v). Total antimony was quantified by employing $\mathrm{HG}$ AAS after the reduction of $\mathrm{Sb}(\mathrm{v})$ to $\mathrm{Sb}(\mathrm{III})$ using a solution containing simultaneously potassium iodide and ascorbic acid.

The concentrations of total antimony and $\mathrm{Sb}(\mathrm{III})$ were calculated considering the relationship between the antimony mass found in the filter and the volume of air collected in $24 \mathrm{~h}$. The results are shown in Table 3. The results demonstrate that for the four samples analyzed, the concentrations of total antimony varied from 4.32 to $4.60 \mathrm{ng} \mathrm{m}^{-3}$; for $\mathrm{Sb}$ (III), they varied from 0.33 to $0.67 \mathrm{ng} \mathrm{m}^{-3}$. These results are in agreement with those found by other authors for antimony in atmospheric particulate matter samples. $^{6-9}$

The limits of quantification for total antimony and $\mathrm{Sb}$ (III) were also calculated on the basis of antimony mass as (ng) and the total air volume collected as $\left(\mathrm{m}^{3}\right)$. The values obtained were 0.5 and $0.2 \mathrm{ng} \mathrm{m}^{-3}$ for total antimony and $\mathrm{Sb}$ (III), respectively. These LQ's values demonstrate that this method is adequate for reliable determination of these analytes in atmospheric particulate matter samples.

\section{Conclusions}

The full two-level factorial design demonstrates that in the conditions established the following factors are statistically significant in the generation of antimony(III) hydride: (1) the sodium tetrahydroborate concentration, (2) the flow rate of sodium tetrahydroborate and (3) the hydrochloric acid concentration. 
The optimized method allows for the determination of total antimony and antimony(III) with the limit of quantification, the precision and the accuracy necessary for analysis of samples containing atmospheric particulate matter.

The concentrations of total antimony and antimony(III) determined in this work are in agreement with those found in studies in other regions.

This paper reports the first application of slurry sampling in conjunction with hydride generation and AAS for speciation analysis of inorganic antimony in airborne particulate matter.

\section{Acknowledgements}

The authors are grateful to Fundação de Amparo a Pesquisa do Estado da Bahia (FAPESB), Conselho Nacional de Desenvolvimento Científico e Tecnológico $(\mathrm{CNPq})$ and Coordenação de Aperfeiçoamento de Pessoal de Nível Superior (CAPES) for providing grants and fellowships and for financial support.

\section{References}

1 M. Filella, P. A. Williams and N. Belzile, Environ. Chem., 2009, 6, 95. 2 P. Smichowski, Talanta, 2008, 75, 2.

3 R. W. Feng, C. Y. Wei, S. X. Tu, S. R. Tang and F. C. Wu, Microchem. J., 2011, 97, 57.

4 P. Smichowski, D. Gómez, C. Frazzoli and S. Caroji, Appl. Spectrosc. Rev., 2008, 43, 22.

5 W. Quiroz, H. Arias, M. Bravo, M. Pinto, M. G. Lobos and M. Cortes, Microchem. J., 2011, 97, 78.

6 C. Dietl, W. Reifenhäuser and L. Peichl, Sci. Total Environ., 1997, 205, 235.

7 P. Smichowski, D. R. Gomez, L. E. Dawidowski, M. F. Gine, A. C. Sanchez Bellato and S. L. Reich, J. Environ. Monit., 2004, 6, 286.

8 J. Moreda-Pineiro, C. Moscoso-Perez, M. Pineiro-Iglesias, P. LopezMahı, S. Muniategui-Lorenzo, E. Fernandez-Fernandez and D. Prada-Rodriguez, Talanta, 2007, 71, 1834.

9 C. Johansson, M. Norman and L. Burman, Atmos. Environ., 2009, 43, 4681.

10 H. R. Hansen and S. A. Pergantis, J. Anal. At. Spectrom., 2008, 23, 1328.

11 D. Sanchez-Rodas, W. T. Corns, B. Chen and P. B. Stockwell, J. Anal. At. Spectrom., 2010, 25, 933.

12 J. Zheng, A. Iijima and N. Furuta, J. Anal. At. Spectrom., 2001, 16, 812.
13 A. Iijima, K. Sato, T. Ikeda, H. Sato, K. Kozawa and N. Furuta, J. Anal. At. Spectrom., 2010, 25, 356.

14 J. Zheng, M. Ohata and N. Furuta, Analyst, 2000, 125, 1025.

15 R. Miravet, J. F. López-Sánchez, R. Rubio, P. Smichowski and G. Polla, Anal. Bioanal. Chem., 2007, 387, 1949.

16 A. Bellido-Martin, J. L. Gomez-Ariza, P. Smichowsky and D. Sanchez-Rodas, Anal. Chim. Acta, 2009, 649, 191.

17 S. L. C. Ferreira, M. Miro, E. G. P. da Silva, G. D. Matos, P. S. dos Reis, G. C. Brandao, W. N. L. dos Santos, A. T. Duarte, M. G. R. Vale and R. G. O. Araujo, Appl. Spectrosc. Rev., 2010, $45,44$.

18 M. J. Cal-Prieto, M. F. Sotelo, A. Carlosena, J. M. Andrade, E. Fernandez and D. Prada, At. Spectrosc., 2006, $27,7$.

19 E. P. Oliveira, L. Yang, R. E. Sturgeon, R. E. Santelli, M. A. Bezerra, S. N. Willie and R. Capilla, J. Anal. At. Spectrom., 2011, 26, 578.

20 E. Ghasemi, N. M. Najafi, S. Seidi, F. Raofie and A. Ghassempour, $J$. Anal. At. Spectrom., 2009, 24, 1446.

21 M. Mulugeta, G. Wibetoe, C. J. Engelsen and W. Lund, J. Anal. At. Spectrom., 2010, 25, 169.

22 P. R. Aranda, P. H. Pacheco, R. A. Olsina, L. D. Martinez and R. A. Gil, J. Anal. At. Spectrom., 2009, 24, 1441.

23 S. L. C. Ferreira, M. D. G. A. Korn, H. S. Ferreira, E. G. P. da Silva, R. G. O. Araujo, A. S. Souza, S. M. Macedo, D. D. C. Lima, R. M. de Jesus, F. A. C. Amorim and M. D. G. A. Korn, Appl. Spectrosc. Rev., 2007, 42, 475.

24 C. R. T. Tarley, G. Silveira, W. N. L. dos Santos, G. D. Matos, E. G. P. da Silva, M. A. Bezerra, M. Miro and S. L. C. Ferreira, Microchem. J., 2009, 92, 58.

25 R. E. Bruns, I. S. Scarminio and B. B. Neto, Statistical DesignChemometrics, Elsevier, Amsterdam, 2006.

26 D. L. Massart, B. G. M. Vandeginste, L. M. C. Buydens, S. de Jong, P. J. Lewi and J. Smeyers-Verbeke, Handbook of Chemometrics and Qualimetrics: Part A, Elsevier, Amsterdam, 1997.

27 S. L. C. Ferreira, R. E. Bruns, H. S. Ferreira, G. D. Matos, J. M. David, G. C. Brandão, E. G. P. da Silva, L. A. Portugal, P. S. dos Reis, A. S. Souza and W. N. L. dos Santos, Anal. Chim. Acta, 2007, 597, 179.

28 E. Fuentes, H. Pinochet, I. De Gregori and M. Potin-Gautier, Spectrochim. Acta, Part B, 2003, 58, 1279.

29 S. M. Macedo, R. M. de Jesus, K. S. Garcia, V. Hatje, A. F. de S. Queiroz and S. L. C. Ferreira, Talanta, 2009, 80, 974.

30 S. M. Macedo, D. C. dos Santos, R. M. de Jesus, G. O. da Rocha, S. L. C. Ferreira and J. B. de Andrade, Microchem. J., 2010, 96, 46. 31 IUPAC, Pure Appl. Chem., 2002, 74, 835.

32 Y. Rodriguez and J. F. Tyson, J. Anal. At. Spectrom., 2006, 21, 757.

33 H. Matusiewicz and M. Krawczyk, J. Anal. At. Spectrom., 2008, 23, 43. 